PURBAWIDYA: Jurnal Penelitian dan Pengembangan Arkeologi p-ISSN: 2252-3758, e-ISSN: 2528-3618 Akreditasi LIPI No. 695/Akred/ P2MI-LIPI/07/2015

Vol. 8 (1), Juni 2019, pp 15 - 27 DOI: https://doi.org/10.24164/pw.v8i1.291

\title{
MENARA MASJID AL-AQSHA KUDUS: ANTARA SITUS HINDU ATAU ISLAM
}

\section{The Minaret of Al-Aqsha Mosque in Kudus: Between Hinduism or Islam}

\author{
Moh. Rosyid \\ Institut Agama Islam Negeri (IAIN) Kudus \\ Jalan Conge Ngembalrejo No. 51, Ngembal Rejo, Ngembalrejo, Kecamatan Bae \\ Kabupaten Kudus, Jawa Tengah 59322 \\ E-mail: mrosyid72@yahoo.co.id \\ Naskah diterima 05 April 2019 - Revisi terakhir 17 Mei 2019 \\ Disetujui terbit 31 Mei 2019 - Tersedia secara online 30 Juni 2019
}

\begin{abstract}
The purpose of this article is to answer of question on the origin of the minaret of $A l$ Aqsha Mosque of Kudus whether its is Hinduism-Buddhism or Islamic site. Data are collected through interview, observation and literature review by means of descriptive analytic method of analysis. This paper shows that archaeological study classified the minaret as an Islamic building based on the Javanese symbols (candra sengkala) engraved in the pillars gapura rusak ewahing jagad. Gapura (gate) refers to 9, rusak means 0, ewahing is 6 and jagad means 1. Read from the last, it refers to the year 1609. The year was the era of Walisongo when Hinduism was declining in Kudus. Hindus and Buddhists people consider the minaret similar to temple based on the architecture and oral tradition. Therefore, further study incorporating history and archaeology need to be conducted.
\end{abstract}

Key words: Kudus minaret, history, site

\begin{abstract}
Abstrak
Tujuan ditulisnya naskah ini adalah untuk memberi jawaban secara ilmiah terhadap polemik keberadaan Menara Masjid Al-Aqsha Kudus, apakah peninggalan HinduBuddha (sebagai candi) atau Islam. Teknik perolehan data dilakukan dengan wawancara, observasi, dan pendalaman literatur. Metode yang digunakan adalah deskriptif analitik. Argumen ilmiah dilakukan dengan pendekatan arkeologi bahwa Menara adalah situs Islam dengan bukti adanya candra sengkala di tiang-atap menara yang tertulis gapura rusak ewahing jagad. Gapura merupakan simbol angka 9, rusak berangka 0, ewahing berangka 6, dan jagad berangka 1 (jadi terbaca dari belakang adalah tahun 1609). Masa itu merupakan era Walisongo ketika umat Hindu sudah tidak eksis di Kudus, sedangkan umat Hindu-Buddha mengandalkan cerita rakyat dan prediksi yang terilhami bentuk bangunan fisik menara yang serupa candi. Untuk mengurai polemik, perlu didapatkan fakta baru dengan riset arkeologi dan dengan pendekatan mutakhir yang melibatkan sejarawan.
\end{abstract}

Kata kunci: Menara Kudus, sejarah, situs 


\section{PENDAHULUAN}

Polemik adanya klaim sepihak bahwa Majapahit merupakan Kerajaan Islam serta Mahapatih Gajah Mada dan Raden Wijaya sebagai muslim mengemuka di jejaring sosial pada Juni 2017. Hal ini direspons oleh arkeolog, budayawan, dan sejarawan dalam diskusi "Sejarah Kerajaan Majapahit" yang diselenggarakan di Jakarta pada Kamis, 22 Juni 2017. Menurut Ketua Masyarakat Sejarawan Indonesia (MSI) yang juga Direktur Jenderal Kebudayaan, Hilmar Farid, hal tersebut perlu diperkuat dengan bukti yang mendasarinya. Jika tanpa bukti, klaim tidak dapat disebut sebagai tafsir baru. Menurut Hasan Djafar, arkeolog, sejak Majapahit berdiri, Islam sudah berkembang, sebagaimana penemuan prasasti batu nisan yang berangka tahun 1203 - 1533 di Kuburan Troloyo yang lokasinya tidak jauh dari Kedaton, ibu kota Majapahit. Pada awal era Majapahit, yaitu tahun 1082 M, di Kerajaan Kediri terdapat masyarakat muslim, yaitu di Gresik, tetapi hingga kini tidak ada bukti adanya benih atau unsur Islam yang diterapkan di Majapahit yang bercorak Hindu-Buddha. Ditemukannya koin perunggu yang bertuliskan huruf Arab $L a$ ilaha illahu diperkirakan berasal pada era Majapahit. Namun, pada masa itu beredar pula koin lain, seperti Cina. Lambang Surya Majapahit di nisan yang berbentuk sinar matahari dengan sudut berujung delapan sering dikaitkan dengan Islam. Lambang ini merupakan penggambaran arah mata angin yang pada setiap arahnya terdapat dewa penguasa. Jadi, tidak ada unsur yang menguatkan bahwa Majapahit merupakan kerajaan Islam. Hal tersebut diperkuat oleh Munandar, arkeolog Universitas Indonesia, bahwa tidak ada nama yang bernuansa Arab pada gelar raja/ratu Majapahit, yang ada bercirikan Hindu dan Buddha ("Kerajaan Majapahit Sangat Jelas Bercorak Hindu," 2017). Paparan tersebut merupakan penegas bahwa polemik keberadaan dan kebenaran sejarah perlu fakta.

Peristiwa masa lalu memberi pesan untuk kehidupan pada manusia. Untuk memahaminya, diperlukan kiprah sejarah. Sejarah merupakan ilmu yang mengulas peristiwa masa lalu. Sejarah dijadikan pula sebagai "senjata" setiap kelompok atau umat beragama dalam mendedahkan fakta pembenar peristiwa masa lalu yang ditorehkan oleh leluhurnya. Untuk mendapatkan pembenar fakta sejarah, dibutuhkan peran arkeologi, yakni ilmu yang mengkaji kebudayaan manusia pada masa lalu berdasarkan data bendawi yang ditinggalkan, di antaranya cagar budaya.

Kota Kudus, Jawa Tengah memiliki peninggalan bersejarah Islam berupa kawasan Kauman Menara Kudus dan situs lain yang terkait. Lestarinya situs tersebut merupakan fakta bahwa Sunan Kudus dan generasi muslim di Kudus hingga kini masih memeliharanya sebagai bentuk toleransi. Jika tidak toleran, tentu peninggalan tersebut sudah dimusnahkan. Situs sejarah dalam kajian ini dipilah menjadi situs pra-Sunan Kudus dan situs era Sunan Kudus. Situs pra-Sunan Kudus adalah Langgar Bubar/Bubrah. Langgar bermakna tempat salat atau rumah. Adapun peninggalan dari era Sunan Kudus di Kudus adalah (Supani, 2009)

1. masjid yang didirikan pra-Masjid Al-Aqsha Menara Kudus (a) Masjid Madureksan yang fungsi awalnya merupakan media untuk mendamaikan orang yang berkonflik. Madureksan dalam bahasa Jawa berasal dari kata 
padu dan rekso. Kini Madureksan berfungsi sebagai masjid, di depan masjid terdapat Kelenteng Hok Ling Bio, di tengah-tengahnya terdapat taman, (b) Masjid Langgar Dalem (ada candrasengkala trisula pinulet nogo, tombak bermata tiga yang dibalut ular naga), (c) Masjid Al-Aqsha/Al-Manar beserta kompleks makam Sunan Kudus, (d) peninggalan Sunan Kudus nonsitus religi, yakni kursi dan tasbih,

2. kediaman Sunan Kudus (diduga di kawasan Masjid Langgar Dalem),

3. situs peninggalan Sunan Kudus berupa alun-alun (yang memisahkan antara Masjid Madureksan dengan Kelenteng Hok Ling Bio) dan infrastruktur yang melekat pada kawasan Masjid Al-Aqsha, seperti sumur resapan pada era Sunan Kudus di area palastren/pawastren (tempat salat bagi perempuan di bagian kanan Masjid Al-Aqsha),

4. peninggalan generasi Sunan Kudus, yakni (a) rumah adat Kudus (identik dengan kediaman saudagar di Kauman Menara Kudus), (b) Madrasah Diniyah Mu'awanatul Muslimin (madrasah diniyah pertama di Kudus, berdiri dari tahun 1918 hingga kini), (c) beberapa pondok pesantren, (d) madrasah dan Yayasan Pendidikan Islam Qudsiyah yang berdiri sejak tahun 1909 hingga kini,

5. tradisi yang berkait dengan peninggalan Sunan Kudus, seperti (a) penjamasan/pencucian Keris Kiai Cinthaka/Cintoko/Ciptoko (perbedaan penyebutan) dan tombak kembar, (b) tradisi buka luwur, yakni memperingati wafatnya Sunan Kudus setiap bulan Sura/Muharam (Kata Sunan ada yang menafsirkan berasal dari kata susuhunan, maksudnya adalah guru dari selatan/Cina),

6. peninggalan Sunan Kudus di luar wilayah Kauman, tetangga wilayah Kauman, seperti Masjid Nganguk Wali (peninggalan Kiai Te Ling Sing/ Tan Liang Sing); (kata kiai ada yang menafsirkan berasal kata kia yang bermakna 'jalan' dan $i$ yang bermakna 'lurus' (pemberi jalan lurus),

7. ada pula masjid kuno di wilayah Kudus yang belum terindentifikasi pendirinya, seperti Masjid Baitul Aziz di Desa Hadipolo, Kecamatan Mejobo yang diprediksi berdiri tahun 863 $\mathrm{H}$ berdasarkan trisula naga di pintu masuk masjid. Masjid ini menjadi cagar budaya sejak tahun 1994, Masjid At-Taqwa di Desa Loram Kulon, Kecamatan Jati, Gapura Masjid Baitul Muttaqin Desa Jati, Kecamatan Jati. Selain situs yang berkaitan dengan Sunan Kudus, di Kudus terdapat situs peninggalan Sunan Muria di Gunung Muria, yakni Masjid dan Makam Sunan Muria.

Dalam tradisi tutur, kawasan Muria yang kini menjadi kawasan Masjid Sunan Muria, semula dihuni oleh Bikhu Resi Ekalaya. Dari sekian banyak situs sejarah tersebut, yang memiliki ciri khas sebagai peninggalan Hindu di kawasan Menara Kudus adalah Menara Masjid Al-Aqsha Kudus yang ditelaah dalam naskah ini.

Dengan adanya peninggalan cagar budaya (CB) tersebut, dapat dinyatakan bahwa Kota Kudus, Jawa Tengah memiliki kawasan CB, yakni Menara Masjid AlAqsha Kudus di Desa Kauman, Kecamatan Kota dan Langgar Bubrah di Dukuh Tepasan, Desa Demangan, Kecamatan Kota. Keduanya berdekatan, tetapi dalam kawasan yang terpisah. Yang dikaji dalam 
riset ini adalah Menara Masjid Al-Aqsha Kudus, yaitu untuk mengetahui benarkah masjid tersebut mempunyai titik hubung dengan Hindu di Kudus pada era Sunan Kudus?

Dalam mengkaji sejarah di Kudus ditemukan ragam situs, di antaranya situs di kawasan Kauman Menara Kudus. Keberadaannya ditafsirkan dalam versi yang beragam, sesuai dengan penafsiran umat beragama, yakni Hindu (di Kudus) dan Islam. Pentingnya riset ini diulas di antaranya karena adanya multipersepsi publik tentang jati diri Menara Kudus dan Langgar Bubrah dalam hal komunitas, yaitu apa dan siapa yang membangunnya. Diperolehnya jawaban dengan hasil kajian ilmiah diharapkan menjadi sumber telaah lintas keilmuan pada fase berikutnya dan hal tersebut tidak menjadi polemik yang kadang-kadang hanya bersumber dari cerita tutur. Pada tahun 1976 Proyek Pengembangan Media Kebudayaan, Departemen Pendidikan dan Kebudayaan, yaitu Pusat Penelitian Purbakala dan Peninggalan Nasional sebenarnya telah mendalami hal ini. Akan tetapi, dengan kajian arkeologi mutakhir diharapkan ditemukan pencerahan.

\section{METODE}

Metode dalam penelitian ini adalah deskriptif analitik, yakni melalui cara mendeskripsikan dan menganalisis data yang berupa bangunan kuno Menara Masjid Al-Aqsha Kudus. Riset ini melakukan kegiatan deskriptif, analitis, dan interpretatif. Mendeskripsikan data berdasarkan fakta dengan kajian ilmiah dilakukan agar diperoleh pembenaran secara ilmiah pula. Paparan fakta menyajikan data antara sumber lisan dengan fakta ilmiah. Berdasarkan tahapan tersebut, hasilnya terpaparkan tentang keberadaan situs dengan pendekatan ilmiah, tidak hanya cerita tutur dan prediksi nonilmiah.

Penelitian ini bertujuan tidak hanya terpublikasi hasil kajian, tetapi hal ini dapat dijadikan pijakan dan arah dalam mewujudkan toleransi lintas umat beragama.

Hasil riset sementara ini menyatakan bahwa Menara Kudus secara arkeologi adalah situs Islam yang dibuktikan dengan tulisan berbahasa Jawa Kuno di menaranya yang ada hingga kini. Pihak yang memprediksi sebagai candi lebih mengedepankan cerita tutur dan prediksi nonilmiah. Agar polemik tidak berkepanjangan, perlu dilakukan riset mutakhir dengan pendekatan yang lebih komprehensif.

\section{HASIL DAN PEMBAHASAN}

Untuk membahas topik ini, kajian diawali dengan memotret keberadaan agama Hindu-Buddha di Nusantara.

\section{Awal Mula Hindu-Buddha di Nusantara}

Ajaran agama apa pun dikembangkan secara luas oleh tokoh agamanya, begitu pula dengan Hindu-Buddha. Menurut Coedes, peninggalan arkeologis dan sumber dari Cina menunjukkan bahwa peradaban Hindu-Buddha pertama di Nusantara pada paruh pertama abad ke-5 $M$ yang dibuktikan dengan adanya prasasti dari Mulawarman di Kalimantan dan dari Purnawarman di Jawa (Coedes, 2010: 90). Prasasti Hindu di Kutai Kalimantan Timur menyebutkan bahwa Raja Mulawarman mendatangkan penganut ajaran Siwa di Kutai. Di Jawa Tengah berkembang agama Hindu Siwa Trimurti, datang pula pengaruh agama Buddha Mahayana. Di 
Jateng antara abad ke-8-10 M berkembang agama Buddha Mahayana dan Hindu Siwa dengan bukti ditemukannya Prasasti Canggal yang berhuruf Pallawa, berbahasa Sanskerta, berangka tahun 732 M di Desa Canggal, Kedu. Prasasti berisi pemujaan kepada Dewa Siwa dalam ajaran Hindu. Di Desa Dinoyo, Malang, Jatim ditemukan Prasasti Dinoyo yang tertulis tahun 760 $\mathrm{M}$, terkait dengan agama Hindu (Darini, 2013: 34). Menurut Munoz, pada abad ke-7 M, keyakinan utama yang dianut di Holing adalah ajaran Siwa. Pada abad ke-8 penyebaran pertapaan Buddha meningkat di bawah kekuasaan Syailendra. Beberapa candi Hindu diubah untuk ajaran Buddha, sebagaimana Candi Bima di dataran tinggi Dieng (Munoz, 2009: 182). Berita dari seorang pendeta Buddha, I'tsing, menyatakan bahwa pada tahun 664 datang pendeta Hwi-ning dan Holing yang dibantu pendeta Jnanabhadra untuk menerjemahkan berbagai Kitab Buddha Hinayana. Dalam berita Tionghoa pada era Dinasti T'ang (618 - $906 \mathrm{M})$ disebut nama Kerajaan Kaling atau Holing di Jawa Tengah yang rakyatnya sejahtera. Sejak tahun $674 \mathrm{M}$ kerajaan tersebut dipimpin Ratu Simo (Dinas Pendidikan Prov Jateng, 2004: 86).

Ada yang memperkirakan bahwa munculnya agama Hindu di Jawa terjadi sebelum Sanjaya menjadi raja di Medang Bhumi Mataram (717 - 760 M). Agama Hindu mencapai puncak kejayaan sesudah Mpu Manuku Rakai Pikatan membangun Candi Siwagrha (rumah siwa) atau Candi Prambanan pada 12 November $856 \mathrm{M}$. Pada era Medang periode di Jawa Tengah, sejak pemerintahan Mpu Manuku Rakai Pikatan hingga era Medang periode Jawa Timur, Kahuripan, Kadiri, Singasari hingga Majapahit orang Jawa, banyak yang beragama Hindu. Era pemerintahan Kartanegara (raja terakhir Singasari) berpaham Siwa Buddha. Kertanegara, sebagai raja, melindungi agama Hindu aliran Siwa sekaligus agama Buddha. Namun, sejak Kesultanan Demak, sebagai kerajaan Islam pertama di Jawa, banyak orang Jawa beralih menjadi muslim. Orang Jawa yang mempertahankan tetap beragama Hindu pindah ke Bali. Setelah Majapahit (Girindrawardhana) ditaklukkan oleh Sultan Trenggono dari Demak tahun 1527, sejak itu agama Hindu mengalami masa surut di Jawa (Achmad, 2017: 27). Akan tetapi, penulis belum menemukan referensi dan fakta sejak kapan agama Hindu ada dan eksis di Kudus.

\section{Menara Masjid Al-Aqsha Kudus}

Menara Masjid Al-Aqsha Kudus (warga Kudus menyebut Menara Kudus) berada di halaman Masjid Al-Aqsha Kudus di Desa Kauman, Kecamatan Kota, Kudus, Jawa Tengah. Bangunan yang menjulang itu menjadi cagar budaya.

Awalnya, di tempat Menara Kudus, dalam cerita rakyat, terdapat sumur yang airnya dipercaya warga sebagai sumber kehidupan. Jika ada orang yang meninggal, lalu diobati dengan air sumur tersebut, orang itu akan hidup lagi. Hal ini membahayakan akidah warga sehingga sumur ditutup dengan bangunan menara. Sumur tersebut, dalam tradisi tutur lainnya, digunakan untuk menimbun kitab-kitab agama Hindu agar kitab tidak dipelajari warga Kudus. Jika kitab tersebut dipelajari, dikhawatirkan warga Kudus memahami ajaran Hindu sehingga menghambat lajunya Islam. Cerita tersebut mengandung pesan yang bermuatan 
kearifan lokal bahwa Menara merupakan bangunan suci yang harus dirawat karena terdapat kitab suci. Fakta lain adalah bahwa berdasarkan riset arkeolog hiasan porselen yang tertempel pada dinding bagian luar bangunan Menara Kudus berjumlah 32 buah, 20 buah berwarna biru bermotif pemandangan alam (masjid, manusia, unta, dan pohon kurma), sedangkan 12 buah lainnya berwarna merah putih dengan motif bunga (Supatmo, 2014: 72). Sakai Takashi dan Takimoto Tadashi, arkeolog Jepang, pada 28 Agustus 2008 datang di Menara Kudus untuk menelusuri asal mula berbagai keramik yang menempel di Menara Masjid al-Aqsha Kudus. Menurut keduanya, dua di antara sekian banyak keramik di Menara Kudus yang menempel di atas pintu bagian utara dan selatan adalah produk pabrik keramik di Vietnam abad ke$14-15$. Keramik di bagian utara berbentuk segi empat, berwarna dasar putih. Adapun bagian tengah berwarna sedikit kebiruan dengan motif bunga. Keramik berusia tua, yaitu dibuat pada abad ke-14 atau sekitar tahun $1450 \mathrm{M}$. Adapun keramik di bagian selatan berbentuk lebih besar, lebih menarik, didominasi warna biru dengan motif bunga yang bercirikan Vietnam dan bentuknya bernuansa Islam. Motif ini dapat ditemukan di Istanbul Turki. Adapun pernik keramik yang sebagian besar ada di Masjid Al-Aqsha umumnya buatan Cina sekitar tahun 1920-an (Rosyid, 2014: 15). Ragam motif serupa juga ada di Gerbang Keraton Kasepuhan Cirebon, Masjid Agung Cirebon, dan Gerbang Makam Sunan Bonang di Tuban. Tradisi pemakaian hiasan piring porselen diilhami oleh hiasan porselen tembok sebagai seni bangunan Islam di Asia Barat dan Asia Tengah pada masa awal perkembangan. Piring porselen di Menara Kudus semula berasal dari Vietnam dan Tiongkok. Karena banyak yang rusak atau lepas, sebagian besar diganti piring porselen dari Belanda (restorasi pada era kolonial Belanda). Porselen yang menempel pada dinding Menara berbentuk piring (lingkaran), bentuk segi empat dengan motif meander yang dikombinasi dengan stilisasi berbentuk bunga dan berbentuk organik yang berasal dari Vietnam. Porselen hias berbentuk seperti kupu-kupu dan bentuk segi empat di atas gerbang paduraksa bagian depan (halaman Masjid AlAqsha), sebagaimana terdapat di Masjid Agung Demak, berasal dari Tiongkok dan Vietnam. Adapun ornamen kaligrafi Arab (khot) di serambi depan Masjid Al-Aqsha yang berupa hiasan gelas patri (stained glass) merupakan hiasan baru yang dibuat setelah penambahan ruang serambi masjid tahun 1933 (Supatmo, 2014: 7275). Menara Kudus versi sejarah lisan merupakan tempat mengumandangkan azan dan menyimpan beduk yang ditabuh menjelang tiba waktu salat lima waktu (hingga kini masih digunakan dua hal itu). Ada juga yang berpendapat bahwa Menara Kudus digunakan sebagai mercusuar atau memandu kapal yang melewati Selat Muria.

Ketika memahami peta riil kondisi bangunan Menara Kudus, terdapat dua pendapat. Pendapat pertama menyatakan bahwa bangunan yang didirikan sebelum orang Islam ada/datang di wilayah Kudus merupakan kelompok Budo. Bangunan Menara Kudus semula berupa sebuah candi yang kemudian berubah fungsi (bentuk menara tersebut mirip dengan Candi Jago di Jawa Timur). Ada pula anggapan bahwa tingginya bangunan menara menjadi tempat memanggil dan mengumpulkan orang. Bangunan ini dapat dibandingkan dengan bale Kulkul di Bali. 
Menurut Roesmanto, bangunan Menara Kudus sering diserupakan bentuknya dengan Bale Kulkul, yakni bangunannya menyerupai menara yang beratap dan tempat kulkul/kentongan agar informasi terdengar jauh dari banjar (desa) dan candicandi di Jawa Timur, seperti Candi Jago (keserupaan ornamen tumpul sebagian unsur asli Indonesia yang terdapat pada susunan tangga di Menara Kudus dan Candi Jago), Candi Kidal, dan Candi Singasari. Persepsi itu akibat (1) adanya keserupaan bentuk antara Menara Masjid Kudus dengan Bale Kulkul, terbuat dari rangka kayu dan adanya kentongan yang tergantung di bawah atap Menara, (2) di Jawa Timur terdapat candi yang memiliki pejal yang tinggi sebagai penyangga bale, sebagaimana Menara Kudus. Ada yang menyatakan bahwa Menara Kudus bercorak Candi Jawa Timur, perpaduan budaya Hindu-Jawa-Islam-Cina dan bercorak Hindu Majapahit. Bangunan Bale Kulkul ada pada setiap kompleks pura (tempat ibadah umat Hindu) dan puri (tempat tinggal keluarga raja) di Bali. Bale Kulkul di banjar (dusun), puri, dan pura pada umumnya terletak di dekat jalan utama lingkungan desa atau jalan antarkota.

Masjid Al-Aqsha Kudus dibangun tahun 1549 M. Dalam perkembangan arsitektur masjid di Jawa, bangunan Menara Kudus merupakan minaret pertama yang melengkapi sebuah masjid (Roesmanto, 2013: 27-29). Menurut Ashadi, Menara Kudus pada mulanya adalah bangunan semacam tetenger yang dibuat oleh komunitas Budo di wilayah yang selanjutnya bernama Kudus dan Sunan Kudus memanfaatkan bangunan itu untuk dakwah. Kata menara dikaitkan dengan keberadaan masjid kuno dan nama
Kota Kudus. Ada dua kemungkinan asal kata. Pertama, perubahan nama dari alManar sesuai dengan apa yang tertulis pada inskripsi di dalam Masjid Menara Kudus. Kedua, sebutan adanya menara (mirip candi) di sebelah tenggara masjid ini sekarang. Ada yang berpendapat bahwa kata menara berasal dari kata almanar, sebagaimana orang dulu menyebut nama didasarkan atas kebiasaan yang dihubungkan dengan kehidupannya. Bangunan besar yang bentuknya mirip candi Hindu lebih menarik perhatian masyarakat Kudus saat itu daripada keberadaan masjid. Penyebutan Masjid Menara Kudus, menurut Ashadi, seolaholah mengandung makna masjidnya menara, masjid milik menara. Dengan demikian, bangunan menara lebih bermakna daripada masjid bagi masyarakat Kudus Kuno. Sebagai perbandingan, Masjid Banten memiliki menara, warga Banten menyebutnya Masjid Banten, bukan Masjid Menara (Banten). Pada awalnya, ada tiga sebutan kaitannya dengan Masjid Menara Kudus, yakni AlManar, Al-Aqsha, dan Al-Quds. Warga kurang familier menyebut ketiga istilah asing (Arab) dan lebih familier menyebut Masjid Menara Kudus (hingga kini). Bisa jadi kata menara diperoleh warga Kudus dari perubahan kata al-Manar atau kata menara sudah ada. Bahkan, sebelum ada kata menara, Al-Manar dan Al-Quds sudah dikenal sebagai nama sebelum nama Kudus, yakni nama tajug. Di tempat itu mungkin sebelumnya telah ada orang yang bermukim yang menganut animisme. Bangunan menara selain sebagai tetenger (penanda) juga sebagai simbol persatuan kelompok masyarakat Kudus Kuno. Menara Kudus adalah axis mundi, sebuah pilar kosmik yang menghubungkan bumi tempat berpijak manusia dengan surga 
sebagai tempat setelah meninggal dunia. Dengan demikian, menara dijadikan pusat peribadatan masyarakat Kudus kuno (Ashadi, 2009: 67-75).

Prediksi Ashadi tersebut perlu didalami secara ilmiah dan persepsi tersebut sederap dengan pemahaman Suparno Boddhi Cakra, pandita Buddha generasi ketiga di Kudus. Menurut tafsiran penulis, 6 Agustus 2018, bahwa Menara Kudus merupakan bangunan Hindu-Buddha selama 60 tahun, tetapi, selanjutnya diberi tambahan kubah bagian atasnya. Ciri penguatnya, lanjut sang pandita, relung di Menara semula digunakan sebagai tempat arca dan bentuk bangunannya sebagaimana candi. PraSunan Kudus di Kudus (sebelumnya di Kesultanan Demak) di Kudus ada Raja Bagus Anom di Kerajaan Barong Keramat, kini di Desa Barongan, Kecamatan Kota, Kudus. Pembuatan candi semula ditolak oleh Ratu Dwarawati, istri Raja Brawijaya, karena model bangunannya tidak berpostur Majapahit sehingga bangunan dipugar dan dibuang atapnya. Ratu Dwarawati saat itu menjadi muslimah setelah diperisteri oleh Sunan Kudus sehingga bangunan (menara) diberi tulisan gapura rusak ewahing jagad, atap candi yang ditambah dengan kubah bagian paling atas dan diberi nama menara, sebelumnya bernama candi atau pura. Kisah ini, menurut sang pandita, bersumber dari Kidung Rumekso ing Wengi anggitan (karya) Sunan Kalijaga bagian Sekar Sinom pupuh $8-10$. Sumber ini apakah dapat dikategorikan sebagai sumber yang ilmiah? Dalam catatan sejarah, Sunan Kudus tidak pernah menikah dengan Dwarawati.

Menurut Sunyoto, Sunan Kudus menikah dengan putrinya, Pecat Tanda Terung dan Dewi Rukhil binti Sunan Bonang (Sunyoto, 2016: 324). Menurut
Salam, Sunan Kudus (Ja'far Shodiq, 700 - 765 M) menikahi puteri Pangeran Tandaterung dan putri Sunan Bonang (Salam, 1977: 10). Perkawinan Sunan Kudus dengan Dewi Rukhil dikaruniai seorang anak lelaki bernama Amir Hasan, sedangkan perkawinan Sunan Kudus dengan puteri Pangeran Pecat Tanda Terung dari Majapahit dikaruniai delapan anak, yakni Nyi Ageng Pembayun, Panembahan Palembang, Panembahan Mekaos Honggokusumo, Panembahan Kodhi, Panembahan Karimun, Penembahan Joko (wafat masih muda), Ratu Pakojo, dan Ratu Probobinabar (menikah dengan Pangeran Poncowati, Panglima Perang Sunan Kudus) (Salam, 1986: 13). Sunan Kudus menikah dengan Dewi Ruhil dan dikaruniai seorang anak, sedangkan perkawinan dengan putri Pangeran Husen (Pecat Tanda Terung) dikaruniai delapan anak (Abdullah, 2015: 97).

Menurut penuturan Ketua Parisada Hindu Dharma Indonesia (PHDI) Kabupaten Kudus, Menara Kudus dalam konteks Hindu lebih tepat disebut rumah kulkul (rumah kentongan), dipukulnya kentongan yang berada di bangunan bagian atas dilakukan untuk mengumpulkan warga dalam kegiatan. Adapun bentuk bangunan Menara Kudus menyerupai candi dengan ciri khas bentuk bangunan yang lancip ke atas dan relief di beberapa titik bangunan menara. Di bagian atas menara terdapat beduk dan kentongan yang hingga kini masih dipukul oleh petugas (marbot) sebagai penanda tibanya waktu salat lima waktu. Jika akan ke bagian atas menara, tersedia tangga yang terbuat dari kayu jati. Sebelumnya, dari dasar menara terdapat tangga/undak-undakan yang terbuat dari tekel yang kanan-kirinya terdapat miniatur candi. Untuk merawat kondisi 
Menara, tidak semua peziarah/wisatawan diperkenankan menaiki Menara.

Dalam catatan Ashadi, pada salah satu tangga (kayu) menara tertera angka tahun 1313 H/1895 M, pada gapura kori sebelah timur bangunan tajuk tertera angka tahun $1210 \mathrm{H} / 1796 \mathrm{M}$, di atas tiang atap bangunan tajuk tertera angka tahun 1145 H/1732 M, di bagian depan pintu masuk makam Sunan Kudus tertera angka tahun Jawa 1895 atau 1296 H/1878 M, di bagian muka dan belakang gapura kori di serambi masjid tertera angka tahun Jawa 1727 (di sebelah barat) dan $1215 \mathrm{H}$ (di sebelah timur) yang keduanya menunjukkan angka tahun 1800 M (Ashadi, 2009: 78). Seni hias (ornamen) pada kompleks Menara Kudus pada bagian luar, teras depan, terdapat beberapa hiasan ukiran batu cadas berpola medalion kecil yang ditempel berjajar dengan motif tetumbuhan menjalar (lunglungan, sulur-suluran). Bingkai lingkaran luar medalion bermotif empat lengkung kurung kurawal (Islami) atau bunga padma (Hinduis). Lingkaran lebih kecil di dalamnya penuh dengan motif sulursuluran dalam posisi melingkar. Ornamen dengan pola piagam paling signifikan ditemukan pada dua lawang kembar, pada posisi kanan-kiri daun pintunya, yang terdapat hiasan berpola piagam bermotif khas stilisasi dedaunan dan sulur-suluran, tetumbuhan khas tropis, meliuk-liuk bercorak seni khas Majapahit. Ornamen berpola medalion banyak dijumpai pada relief Candi Penataran di Jawa Timur dengan motif sulur-suluran dan stilisasi pengaburan figur binatang, seperti singa, gajah atau burung. Dengan demikian, hiasan berpola medalion di Masjid Menara Kudus merupakan pola kesinambungan tradisi seni hias pra-Islam (Supatmo, 2014: 76).
Adapun pendapat yang menyatakan Menara Kudus merupakan situs Islam dengan dalih menara sejak semula dibangun muslim di Kudus karena (1) sejak berdirinya, yaitu tahun 1609 Saka/1685 M (tahun 1609, dibuktikan adanya tulisan Bahasa Jawa Kuno di papan jati yang terdapat di menara bagian atas/puncak hingga kini, dekat dengan beduk) menjadi simbol peribadatan Islam, (2) orientasi bangunan menara sama dengan orientasi bangunan masjid, dan (3) adanya perbedaan bangunan Menara Kudus (hanya ada satu bangunan) jika candi tidak hanya satu bangunan, tetapi ada pelengkapnya.

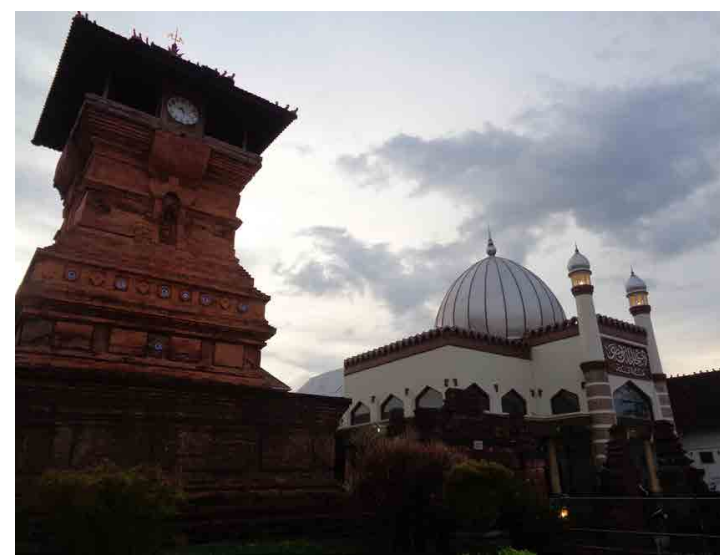

Gambar1. Menara Masjid (Sumber: Koleksi Penulis, 2018)

Dalam arkeologi, bukti masa pembuatan merupakan data utama, jika tidak ada angka/tahun, dicari bukti lain, misalnya melakukan ekskavasi di sekitar bangunan. Hasil ekskavasi, misalnya arang dan keramik, dapat dijadikan bahan penentuan umur bangunan. Akan tetapi, bukti arkeologis yang masih ada, yaitu tulisan berhuruf Jawa Kuno menandakan tahun 1609 M. Menurut Tjandrasasmita, sebelum kedatangan Islam di Indonesia, yang lazim dikenal dengan zaman kerajaan Indonesia Hindu-Buddha (abad 
ke-4 sampai dengan $16 \mathrm{M}$ ), jenis tulisan (aksara) yang digunakan pada prasasti dan naskah kuno ialah tulisan pallawa, pranagari, Jawa Kuno (kawi), Sunda Kuno, dan Bugis. Sejak abad ke-7 M pada prasasti Kerajaan Sriwijaya di Kedukan Bukit, Talang Tuwe, Telaga Batu, Kota Kapur, Merangin, Alas Pasemah, dan lain-lain belum menggunakan tulisan Jawa, tetapi bahasa Melayu Kuno sudah digunakan yang bercampur dengan bahasa Sanskerta (Uka Tjandrasasmita, 2009). Dengan demikian, tulisan Jawa di Menara Kudus sebagai penanda bangunan menara dibuat setelah era Hindu-Buddha di Indonesia atau era Islam.

Untuk memperkuat fakta siapa yang membuat Menara Masjid Al-Aqsha Kudus, dapat dipahami makna kata candi. Candi berasal dari kata candika yang berarti nama perwujudan Dewi Durga sebagai dewi kematian sehingga candi selalu dihubungkan dengan monumen tempat pedarmaan untuk memuliakan raja yang sudah wafat (anumerta), seperti Candi Kidal untuk memuliakan Raja Anusapat. Candi tidak hanya menyebut tempat ibadah, candi juga merupakan situs purbakala nonreligius pada era HinduBuddha Indonesia klasik, baik sebagai istana (keraton), pemandian (petirtaan), maupun gapura. Candi di Indonesia identik dengan tempat ibadah umat Hindu dan Buddha. Contoh candi Hindu ialah Prambanan, Gebang, Dieng, Gedong Songo, Panataran, dan Cangkuang. Contoh candi Buddha ialah Borobudur, Sewu, Kalasan, Sari, dan Plaosan. Adapun candi berfungsi (1) tempat pemujaan, (2) sarana ziarah, tempat menyimpan abu jenazah dan kerangkanya, seperti Candi Borobudur, Sumberawan, dan Muaratakus, (3) pedarmaan, yakni candi (kadang kala milik pribadi) yang digunakan untuk memuliakan arwah raja atau tokoh penting yang wafat, seperti Candi Belahan tempat Airlangga sebagai perwujudan Wishnu yang menunggang garuda, (4) pertapaan, seperti Candi Gedong Songo, Liyangan di lereng timur Gunung Sundoro, (5) wihara sebagai tempat biksu atau pendeta bersemadi, (6) gerbang yang berfungsi sebagai jalur masuk, (7) petirtaan yang berada di dekat sumber mata air sebagai tempat pemandian. Ketujuh kriteria candi tersebut tidak terdapat pada Menara Kudus.

\section{Urgensi Riset Arkeologi Mutakhir dalam Mengurai Polemik}

Program Unit Penelitian Proyek Pembinaan Kepurbakalaan dan Peninggalan Nasional, Proyek Pengembangan Media Kebudayaan, Departemen Pendidikan dan Kebudayaan Tahun 1976 melakukan ekskavasi pada 17 April - 17 Mei 1976 di Kudus, khususnya Kompleks Masjid Menara Kudus, Bukit Begawan (Rahtawu), dan Langgar Bubrah. Ketiga lokus memiliki watak situs yang berbeda. Tujuan ekskavasi adalah meneliti aspek arkeologis situs Masjid Al-Aqsha dan Langgar Bubrah. Kedua bangunan bercirikan gaya peralihan era Indonesia Hindu ke masa Indonesia Islam (Ambary, Djafar, Romli, \& Awe, 1978). Penelitian arkeologi tersebut perlu dikembangkan lagi agar dapat menjawab dinamika yang dianggap persoalan oleh publik dalam hal yang mana yang lebih mendekati kebenaran, yaitu Menara Kudus merupakan peninggalan Hindu, Jawa Kuno, Islam, atau masa peralihan.

Menara Masjid Al-Aqsha Kudus berada di Desa Kauman, Kecamatan Kota, Kudus. Tinggi bangunan menara 
$18 \mathrm{~m}$, luasnya $10 \mathrm{~m}$ persegi, bahan bakunya terbuat dari batu, bata merah, sirap, dan semen. Menara dihiasi antefiks (hiasan yang menyerupai bukit kecil). Bangunannya meliputi kaki, tubuh, dan puncak yang disertai adanya ukir bermotif Jawa-Hindu. Menara diprediksi dibuat tahun 1609 Tahun Jawa/1685 M berdasarkan candra sengkala di salah satu tiang atap menara yang tertulis gapura rusak ewahing jagad. Gapura sebagai simbol angka 9, rusak berangka 0 , ewahing berangka 6, dan jagad berangka 1 , jadi membacanya dari belakang (tahun 1609). Prediksi ini perlu didalami dengan pendekatan arkeologis mutakhir dengan bantuan ilmu lain. Keberadaan arkeologi merekonstruksi sejarah kebudayaan dan cara hidup manusia serta proses budayanya pada masa lalu. Untuk menggapai tujuan itu, semua peninggalan masa lalu sebagai objek studi ditinjau dari segi bentuk, fungsi, proses pembuatan, dan sebagainya. Objek arkeologi adalah semua peninggalan masa lalu yang masih dapat ditemukan.

Hal yang harus didalami ulang dengan kajian arkeologi adalah (a) kapan sebenarnya tahun didirikannya Menara Kudus dengan mendalami pemaknaan candra sengkala di salah satu tiang atap menara yang tertulis gapura rusak ewahing jagad. Menurut tafsiran Soecipto Wiryosuparto dalam memaknai tulisan tersebut, gapura sebagai simbol angka 9 , rusak berangka 0 , ewahing berangka 6 , dan jagad berangka 1 (jadi terbaca dari belakang tahun 1609). Hal lain yang perlu digali untuk diperoleh fakta baru adalah bagaimana kondisi geografis kawasan Menara Kudus pada era itu dan seperti apa kondisi sosial masyarakat Kudus tatkala dibangun Menara Kudus. Terjawabnya pertanyaan tersebut untuk menemukan kebenaran fakta. Hanya saja, menurut Purwadi, sebelum Sunan Kudus hidup di Kudus (sebelumnya di Kerajaan Demak), masyarakat Kudus didominasi penganut Hindu. Sunan Kudus pun memasukkan kebiasaan mereka dalam syariat Islam secara halus, misalnya, pada Hari Raya Idul Qurban menyembelih kerbau sebagai penghormatan, bukan sapi karena sapi merupakan hewan yang dimuliakan umat Hindu. Sunan Kudus pun membangun menara untukazan dengan desain bangunan Hindu (Purwadi \& Maharsi, 2012: 136). Sapi/lembu dimuliakan karena asal mula diciptakan mereka dijadikan kendaraan Dewa Siwa. Awalnya Brahma memerintah pada Daksa untuk menciptakan sapi tatkala Siwa bertapa terkena tumpahan susu anak sapi yang sedang menyusu induknya. Agar Siwa tidak marah karena tapa terganggu, Daksa menghadiahkan seekor sapi jantan pada Siwa untuk dijadikan kendaraan (vahana) (Dinas Pendidikan Prov Jateng, 2004: 106).

Hal yang harus dipahami Pemda Kudus adalah bahwa nilai unggul kampung Menara Kudus perlu dipertahankan. Menurut Nurini, keunggulannya berupa nilai estetis (1) perpaduan ornamen Buddha, Hindu, dan Islam yang tecermin dalam bangunan masjid, menara, kompleks makam, (2) kemajemukan, adanya tajuk dan gapura yang mencerminkan budaya Hindu, (3) kelangkaan, hanya di Kudus (Nurini, 2011: 15). Selain itu, keunggulan Kampung Menara adalah adanya rumah adat kudus yang memiliki tata ruang khas yang meliputi jogosatru, ruang inti (ruang dalam), dan pawon (Ekarini, 2016: 56). Menurut Hardiansyah, menara memiliki atap berbentuk rumah tipe payon tanpa hiasan ukiran. Setelah Sunan Kudus berkiprah, terjadi perubahan bentuk fisik 
dan interior yang didominasi ukiran dari berbagai kebudayaan (Hardiansyah, 2009: 19). Akan tetapi, kini rumah adat yang tersisa hanya dua rumah di Kampung Kauman Menara Kudus. Dari sisi tata letak, Kampung Menara terkesan kumuh. Menurut Anisa, bentuk lingkungannya merupakan gambaran rumah kilungan yang menyimpan alasan tersendiri (Anisa, 2004: 5). Nilai positif yang perlu dilestarikan adalah bahwa Sunan Kudus dan generasinya membangun situs Islam yang diserupakan dengan candi sebagai bentuk respek. Ada situs Hindu di Kudus yang berdekatan dengan Menara Kudus, yakni Langgar Bubrah yang memiliki kekhasan sebagai situs Hindu, yakni adanya yoni dan lingga yang masih utuh hingga kini, tidak dihilangkan situs Hindu di Kudus, tetapi mengakulturasikannya sebagai bentuk respons positif. Generasi pengelola kawasan Menara Kudus kini merawat situs akulturasi.

\section{SIMPULAN}

Dalam arkeologi, bukti masa pembuatan sebagai data utama, sebagaimana candra sengkala di tiang-atap Menara Kudus tertulis gapura rusak ewahing jagad. Maknanya adalah gapura simbol angka
9, rusak berangka 0, ewahing berangka 6, dan jagad berangka 1 (jadi terbaca dari belakang tahun 1609). Dengan demikian, Menara Kudus dibuat pada era Walisongo menyebarkan Islam di Jawa. Masa pembuatan menaranya tatkala umat Hindu sudah tidak dominan di Kudus sehingga kecil kemungkinan membuat candi karena setelah Majapahit ditaklukkan Sultan Trenggono, Raja Demak tahun 1527 M, umat Hindu mengalami masa surut di Jawa dan berpindah ke Bali.

Selama ini, anggapan pandita Buddha dan tokoh Hindu di Kudus yang menyatakan bahwa Menara Masjid Kudus semula candi hanya berdasarkan cerita tutur, bukan sumber ilmiah.

\section{Ucapan Terima Kasih}

- Penulis mengucapkan terima kasih kepada Humas Yayasan Masjid, Menara, dan Makam Sunan Kudus, Bapak Deni Nur Hakim, yang berkenan sebagai sumber data, kepada pandita Buddha di Kudus, Bapak Suparno Boddhi Cakra, dan Ketua Parisada Hindu Dharma Indonesia (PHDI) Kabupaten Kudus, Bapak I Putu Dantra yang berkenan sebagai narasumber.

\section{DAFTAR PUSTAKA}

Abdullah, R. (2015). Walisongo Gelora Dakwah dan Jihad di Tanah Jawa (1404--1482 M). Sukoharjo: Al Wafi.

Achmad, S. W. (2017). Asal-Usul Sejarah Orang Jawa. Yogyakarta: Araska.

Ambary, H. M., Djafar, H., Romli, M., \& Awe, R. D. (1978). Laporan Ekskavasi Kudus. In Berita Penelitian Arkeologi No. 14 (hal. 24-67). Jakarta: Proyek Pengembangan Media Kebudayaan, Departemen P \& K.

Anisa. (2004). Rumah dalam Kilungan di Kota Lama Kudus Analisis Konsep Bangunan. Jurnal Nalars, 3 (1), 17-23.

Ashadi. (2009). Menara Kudus sebagai Aksis Mundi: Menelusuri Komunitas Kudus Kuno. Jurnal Nalars, 6 (1), 12-24. 
Coedes, G. (2010). Asia Tenggara Masa Hindu Buddha. Jakarta: KPG; Ecole Francoise d' Extreme-Orient; Forum Jakarta Paris; Puslitbang Arkenas.

Darini, R. (2013). Sejarah Kebudayaan Indonesia Masa Hindu Buddha. Yogyakarta: Ombak.

Dinas Pendidikan Prov Jateng, M. R. (2004). Artefak Batu Masa Prasejarah Hindu-Buddha (Koleksi Museum Ronggowarsito). Semarang: Dinas Pendidikan Provinsi Jawa Tengah.

Ekarini, D. (2016). Dilema Pelestarian Rumah Adat Kudus. Jurnal Konservasi Cagar Budaya Borobudur, 10 (1), 15-24.

Hardiansyah, M. (2009). Rumah Tradisional Kudus: Pengaruh Budaya Islam (1500-1900). UIN Jakarta.

Kerajaan Majapahit Sangat Jelas Bercorak Hindu. (2017, Juni). Kompas, hal. 12.

Munoz, P. M. (2009). Kerajaan Awal Kepulauan Indonesia dan Semenanjung Malaysia Perkembangan Sejarah dan Budaya Asia Tenggara (Zaman Prasejarah hingga Abad $X V I)$. Yogyakarta: Mitra Abadi.

Nurini, N. (2011). Kajian Pelestarian Kampung Kauman Kudus sebagai Kawasan Bersejarah Penyebaran Agama Islam. Teknik, 32(1), 9-17. https://doi.org/10.14710/Teknik. V32I1.1685

Purwadi, \& Maharsi. (2012). Babad Demak Sejarah Perkembangan Islam di Tanah Jawa. Yogyakarta: Pustaka Utama.

Roesmanto, T. (2013). Rupa Bentuk Menara Masjid Kudus, Bale Kulkul, dan Candi. Jurnal Arsitektur 2 (2), 2, 12-24.

Rosyid, M. (2014). Esai-Esai Toleransi. Yogyakarta: Idea Press.

Salam, S. (1977). Kudus Purbakala dalam Perjuangan Islam. Kudus: Menara Kudus.

Salam, S. (1986). Ja'far Shodiq Sunan Kudus. Kudus: Menara Kudus.

Sunyoto, A. (2016). Atlas Walisongo. Depok: Pustaka Iman dan Lesbumi PBNU.

Supani, S. D. (2009). Benda Cagar Budaya Peninggalan Sejarah dan Purbakala Kabupaten Kudus. Kudus: Dinas Kebudayaan dan Pariwisata Kabupaten Kudus.

Supatmo. (2014). Keunikan Ornamen Bermotif Figuratif pada Kompleks Bangunan Masjid Menara Kudus. Imajinasi : Jurnal Seni, 7(1), 63-80.

Uka Tjandrasasmita. (2009). Arkeologi Islam Nusantara. Jakarta: KPG. 
PURBAWIDYA Q Vol. 8, No. 1, Juni 2019 